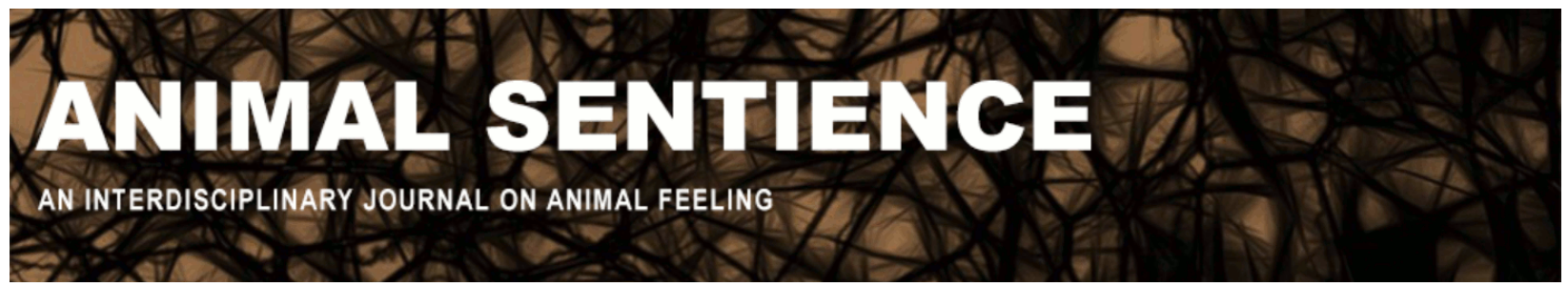

Vonk, Jennifer (2017) What can research on nonhumans tell us about human dissonance?. Animal Sentience 12(2)

DOI: $10.51291 / 2377-7478.1192$

Date of submission: 2017-02-02

Date of acceptance: 2017-02-07

(c) $\underset{\mathrm{EY}}{\mathrm{C}}$

This article has appeared in the journal Animal

Sentience, a peer-reviewed journal on animal

cognition and feeling. It has been made open access,

free for all, by WellBeing International and deposited

in the WBI Studies Repository. For more information,

please contact

wbisr-info@wellbeingintl.org.

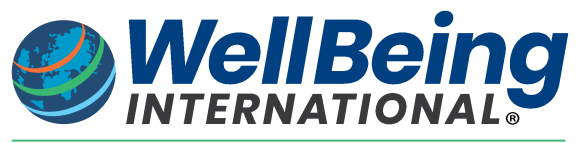

SOLUTIONS FOR PEOPLE, ANIMALS AND ENVIRONMENT 


\title{
What can research on nonhumans tell us about human dissonance?
}

Commentary on Zentall on Cognitive Dissonance

\author{
Jennifer Vonk \\ Oakland University, Rochester, MI
}

\begin{abstract}
Zentall's thoughtful review of the literature on cognitive dissonance in nonhumans helps to highlight the common finding that similar outcomes in humans and nonhumans can be attributed to different underlying mechanisms. I advocate a more fully comparative approach to the underlying mechanisms, avoiding the assumption of shared processes in humans and nonhumans.
\end{abstract} Keywords: cognitive dissonance, human, nonhuman, comparative

\begin{abstract}
Jennifer Vonk is an associate professor at Oakland University in Rochester, Michigan. She is the director of the Laboratory of Cognitive Origins, and has studied a wide range of cognitive processes and behaviors in a wide range of species, resulting in 50 peer-reviewed journal publications and more than 30 edited chapters and commentaries. http://www.jennifervonk.com/
\end{abstract}

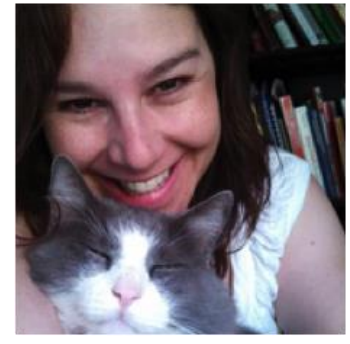

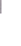


\& Beran, 2012); yet, there is good evidence that at least some species are aware of their own memory processes. Such evidence has been presented in dolphins, nonhuman primates, and in rats, but, to my knowledge, there is no convincing evidence yet for metacognitive processes in pigeons (for review see Smith, 2009, although see Castro \& Wasserman, 2013). Pigeons do, however, reveal the same apparent dissonance effects. The presence of dissonance effects in animals without clear metacognition appears to support Zentall's claims that such effects can be attributed to simpler mechanisms that do not rest upon concerns with social judgments. Furthermore, the fact, noted by Zentall, that humans are not always aware of the association between effort and the cue that follows it suggests that, even in humans the effects do not arise from a conscious evaluative process.

Another strategy for linking dissonance effects to other cognitive phenomena would be to study dissonance effects in populations with autism. Although I am not aware of any literature that supports this assumption, individuals with autism would presumably fail to show the same kind of concern with presenting consistent beliefs and attitudes to their peers. This is because they exhibit deficits in reasoning about the thoughts and beliefs of others, and thus would have reduced motivation to alter their behavior to appear more consistent to others. Thus, they might be expected to show similar contrast effects without the subsequent need to justify that behavior.

Similar effects across species do not necessarily imply similar underlying mechanisms. I do not believe that Zentall makes this common mistake. But to argue that dissonance effects in humans are not due to the desire to rectify perceived inconsistencies on the grounds that animals show similar effects in the absence of self-evaluative processes would be to neglect the possibility that animals engage in behaviors similar to those of humans for very different underlying reasons. For example, humans may prefer to make visual gestures to other humans who they know can see them. Chimpanzees too may gesture to others who can see their gesture, but this strategy may be due to a learned association between the visibility of another's eyes and their responsiveness to requests rather than to an understanding of "seeing" (Povinelli \& Vonk, 2004). This is not to say that researchers should abandon studying similar behaviors across species to elucidate underlying mechanisms. Such an approach can certainly clarify which abilities are necessary and sufficient for the expression of specific behaviors and cognitions. For example, it is clear that language and perhaps metacognitive abilities are unnecessary for shifts in preferences among cues that signal identical rewards after differential effort. However, dissonance effects in humans may well arise precisely because of our unique capacity to reflect upon our own (sometimes conflicting) beliefs and behaviors.

Zentall's review highlights some other intriguing aspects of the work on dissonance in nonhumans. It is puzzling that animals would prefer a cue that signaled the lack of food. This is worth exploring in greater detail. Associationist theories cannot account fully for such a pattern of results unless the association between the animal's state of arousal and the cue takes precedence over the association between the cue and the reward (or lack thereof). However, Clement and Zentall (2002) showed that differential arousal is not necessary to obtain contrast effects. It is therefore possible that differential desire rather than differential arousal explains some of the effects. For example, individuals that work harder or anticipate having to work harder (whether through cognitive or physical effort) find food more desirable. This parallels the somewhat controversial research on glucose depletion where even cognitive effort requires 
glucose (Miller, 2012). That is, the reward itself, or the cue that signals it, may become more appealing when one has depleted more energy. I am not convinced that the control for arousal or physical effort at the time of choice necessarily accounts for this. Zentall describes some work showing that animals prefer stimuli associated with food under conditions when they were food deprived over stimuli associated with food under conditions when they were less food deprived; they maintain such preferences under identical conditions of deprivation (Marsh, Schuck-Paim, \& Kacelnik, 2004). Perhaps once the animal is sated, the cue associated with food is associated with lack of desire rather than with the intense need state that is still experienced when food is not present.

Animals have sometimes been reported to behave more optimistically under conditions when they anticipated but did not receive a reward in cognitive bias paradigms (Burman et al., 2011; Briefer Freymond et al., 2014). In nonhumans, cognitive bias is often assessed by presenting animals with a pair of cues; one signals reward and the other signals lack of reward or an aversive outcome (Harding, Paul, \& Mendl, 2004). Once animals have learned the different outcomes associated with each cue, they are presented with ambiguous stimuli, which typically fall along intermediate values of a spatial or perceptual continuum. Animals are assessed for their response to the ambiguous stimuli, which is then compared to their previously trained responses to the reward and nonreward cues. If they respond to ambiguous cues as if they are anticipating reward, the animals are deemed to be behaving optimistically. Studies of cognitive bias in nonhumans are useful from a welfare perspective, as they can indicate what events or stimuli may cause animals to behave pessimistically or optimistically. However, they have often yielded contradictory or confusing patterns of results (McGuire, Vonk, Fuller, \& Allard, 2017). If the nonreward outcome ends up being more valued due to a greater contrast between the effort to access that cue and the end result, animals may appear to behave pessimistically when it is predicted that they will be optimistic. Perdue (2017) has recently shown that, in the absence of any manipulation intended to influence underlying affect, animals tend to respond to intermediate stimuli the way they respond to the nonrewarded stimulus over repeated exposure. These preferences reverse when reward contingencies are reversed - an effect that Perdue attributes to contrast effects rather than to shifts in underlying biases, drawing another interesting parallel with the work on dissonance.

Zentall suggests that the very presence of contrast effects implies a form of relational learning. I would like to see his thinking on this point further articulated. It is known that some apes implicitly recognize the relations between sets of objects (Vonk, 2003). Many species can understand a single relation (e.g., sameness, difference), but fewer species appear capable of second-order relations in which they understand that the relationship between two objects or events is the same as the one between two other objects or events. Some authors have argued that relational knowledge is a key cognitive trait separating humans from nonhumans (Penn, Holyoak, \& Povinelli, 2008). Thus, the type of relational knowledge assumed to underlie cognitive dissonance effects needs further elaboration.

In addition to the tendency to preferentially value rewards that one has worked harder to obtain, individuals demonstrate dissonance by devaluing rewards they have previously rejected in a forced choice (Brehm, 1956). The adaptive function of a tendency to devalue items that have previously not been chosen may be easier to understand in humans than in nonhumans. For example, once humans detect their own inconsistency, they may try to resolve 
it because inconsistency introduces undesirable unpredictability in a social setting. Thus, the bias may be adaptive in modulating social relations. However, one must be careful to avoid conflating current function with the original function that allowed a trait to evolve in a population. It is not clear what evolutionary pressures would select for the bias in such a broad range of species. Zentall's within-trial contrast model suggests that such biases would encourage animals to work harder to obtain rewards, perhaps when there is a greater risk under conditions of limited or risky resources. There is also the possibility that the bias was not selected for but a natural byproduct of the relationship between exertion and reward. This explanation is not as clear where there is denigration of previously unselected rewards, however.

West, Jett, Beckman, and Vonk (2010) used the "spreading of alternatives" paradigm to assess changes in animals' preferences for rewards formerly valued similarly after one of the options was not chosen on a previous trial. They found that only monkeys, but not psitaccines or bears, selected the previously unchosen option less often on a final trial. This is consistent with the idea that they devalued the option they had not selected. However, chimpanzees also failed to show a pattern consistent with dissonance. Despite this anomaly, we argued that perhaps this form of dissonance evolved in the primate lineage, especially given similar results in monkeys reported by Egan, Santos, and Bloom (2007). Chen and Risen (2009) criticized the Egan et al. (2007) study, suggesting that similar response times to retrieve the rewards are not necessarily indicative of equivalent preferences. However, West et al. (2010) used the number of choices of each item rather than response times to establish equivalent preference rates. As far as I'm aware, this the only study to examine apparent dissonance effects in several distantly related species using exactly the same task. A broad comparative approach might be useful in determining the extent to which similar mechanisms underlie similar behaviors.

Rather than questioning Zentall's approach to the study of cognitive dissonance, or his interpretation of the results of such studies, I hope I have highlighted a few directions in which the current research could be extended for a better understanding of the mechanisms underlying such behavior in both humans and nonhumans.

\section{References}

Brehm, J. W. (1956). Postdecision changes in the desirability of alternatives. Journal of Abnormal and Social Psychology, 52, 384-389.

Briefer Freymond, S., Briefer, E. F., Zollinger, A., Gindrat-von Allmen, Y., Wyss, C., \& Bachmann, I. (2014). Behaviour of horses in a judgment bias test associated with positive or negative reinforcement. Applied Animal Behaviour Science, 158, 34-45.

Burman, O., McGowan, R., Mendl, M., Norling, Y., Paul, E., Rehn, T., \& Keeling, L. (2011). Using judgement bias to measure positive affective state in dogs. Applied Animal Behaviour Science, 132, 160-168.

Castro, L., \& Wasserman, E. A. (2013). Information-seeking behavior: Exploring metacognitive control in pigeons. Animal Cognition, 16, 241-254.

Chen, M. K., \& Risen, J. L. (2009). Is choice a reliable predictor of choice? A comment on Sagarin and Skowronski. Journal of Experimental Social Psychology, 45, 425-427. 
Clement, T. S., \& Zentall, T. R. (2002). Second-order contrast based on the expectation of effort and reinforcement. Journal of Experiment Psychology: Animal Behavior Processes, 28, 6474.

Egan, L. C., Santos, L. R., \& Bloom, P. (2007). The origins of cognitive dissonance: Evidence from children and monkeys. Psychological Science, 18, 978-983.

Harding, E. J., Paul, E. S., \& Mendl, M. (2004). Animal behaviour: Cognitive bias and affective state. Nature, 427, 312.

Marsh, B., Schuck-Paim, C., \& Kacelnik, A. (2004). Energetic state during learning affects foraging choices in starlings. Behavioral Ecology, 15, 396-399.

McGuire, M., Vonk, J., Fuller, G., \& Allard, S. (2017). Using an ambiguous cue paradigm to assess cognitive bias in gorillas (Gorilla gorilla gorilla) during a browse manipulation. Animal Behavior and Cognition, 4.

Miller, H. C. (2012). The role of glucose on executive control vigor: Evidence in support of comparative research. International Journal of Comparative Psychology, 25, 208-220.

Penn, D. C., Holyoak, K. J., \& Povinelli, D. J. (2008). Darwin's mistake: Explaining the discontinuity between human and nonhuman minds. Behavioral and Brain Sciences, 31, 109-130.

Perdue, B. M. (2017). Mechanisms underlying cognitive bias in nonhuman primates. Animal Behavior and Cognition, 4, 51-69. doi: 10.12966/abc.05.02.2017

Povinelli, D. J., \& Vonk, J. (2004). We don't need a microscope to explore the chimpanzee's mind. Mind and Language, 19, 1-28.

Smith, J. D. (2009). The study of animal metacognition. Trends in Cognitive Sciences, 13, 389396.

Smith, J. D., Coutinho, M. V. C., Boomer, J., \& Beran, M. J. (2012). Metacognition across species. In J. Vonk \& T. K. Shackelford (Eds.), The oxford handbook of comparative evolutionary psychology (pp. 274-291). New York, NY: Oxford University Press.

Vonk, J. (2003). Gorilla (Gorilla gorilla gorilla) and Orangutan (Pongo abelii) understanding of first and second order relations. Animal Cognition, 6, 77-86.

West, S., Jett, S. E., Beckman, T., \& Vonk, J. (2010). The phylogenetic roots of cognitive dissonance. Journal of Comparative Psychology, 124, 425-432.

Zentall, T. R. (2016). Cognitive dissonance or contrast? Animal Sentience, 12(1). 